[A large number of contributions described various means of popularizing and teaching astronomy. As many relied heavily on illustrations that cannot be reproduced here, or on practical demonstrations, these contributions are covered by the following report, which emphasizes the salient points in each paper.

Two contributions dealt with general questions affecting popularization of astronomy, and they were accompanied by four contributions describing different, practical methods of conveying information to various audiences, including a special campaign in a a rather unlikely site - the Paris Métro. - Eds.]

\title{
Opening the Sky to Everyone
}

\section{Joel Chanoir}

CEMEA, 43 bis rue des Moissons, F-51100 Rheims, France

CEMEA [Centres d'Entraînement aux Méthodes d'Education Active - Centres for Training Methods of Active Education] exists to encourage better understanding of science among teachers, organisers of youth groups, leaders of summer camps, etc. Its activities with regard to astronomy were described.

[Text not received - Eds.]

\section{Interesting Business in Astronomy}

\section{Michel Lyonnet du Moutier}

23 av. des Bleuets, F-92700 Colombes, France

Support from firms is of increasing importance in amateur astronomy. Two projects were described. In the first, a company running a winter resort in Argentina was persuaded to hold Halley observation sessions at their site in the Cordillera de los Andes. A similar event was later held by the same company at a new resort in southern France. The second project involved interesting a professional journal for construction engineers in producing a special issue devoted to Comet Halley. This was speedily exhausted, most of the demand for back numbers coming not from the engineers themselves but from their families. 